\title{
A NECESSÁRIA VINCULAÇÃO DO DESENVOLVIMENTO ECONÔMICO AOS DIREITOS FUNDAMENTAIS POR CONTA DAS CARTAS DA ONU E SEUS REFLEXOS NA CONSTITUIÇÃO BRASILEIRA DE 1988
}

Caricielli Maisa Longo ${ }^{1,}$ Marcelo Pereira Longo ${ }^{2}$

${ }^{1}$ Graduada em Direito (UFMS - Universidade Federal de Mato Grosso do Sul - Campus Três Lagoas) e Mestranda em Direito (Centro Universitário Toledo - Unitoledo-SP), Professora voluntária da graduação (Prática Jurídica Real e Orientações Monográficas) na UFMS/CPTL. Advogada. ${ }^{2}$ Mestre em Direito. Professor da Universidade Federal do Mato Grosso do Sul - Campus de Três Lagoas.

\section{RESUMO}

O presente artigo pretende associar desenvolvimento econômico e direitos fundamentais, tomando por base o texto constitucional brasileiro de 1988 e cartas da ONU, que tratam sobre o tema, tendo em vista a preocupação com o bem estar e dignidade do ser humano.

Palavras-chave: Direitos Fundamentais; Desenvolvimento econômico; Constituição Brasileira de 1988; Cartas da ONU.

REQUIRED ATTACHMENT TO THE ECONOMIC DEVELOPMENT OF FUNDAMENTAL RIGHTS ON BEHALF OF LETTERS TO THE UN AND ITS CONSEQUENCES IN THE BRAZILIAN CONSTITUTION OF 1988

\section{ABSTRACT}

This article seeks to associate economic development and rights, based on the 1988 Brazilian Constitution and UN Charter, which related to the matter in view of the concern for the welfare and human dignity.

Keywords: Fundamental Rights, Economic Development, the 1988 Brazilian Constitution, Charters of the UN. 


\section{INTRODUÇÃO}

O propósito da atividade humana, dentre outras, deve ser o de manter a paz e promover o bem estar das pessoas, levando em conta a necessidade da efetivação da dignidade. O desenvolvimento econômico é um importante caminho para isto. Ressalta-se que em função do desenvolvimento o ser humano consegue sair do ideal de mera sobrevivência para a busca e realização de uma existência confortável que reflete não só no aumento da expectativa média de vida, mas, principalmente, na busca incessante de que esta vida seja digna.

A Organização das Nações Unidas dentre os seus vários propósitos, ressalta o de "realizar a cooperação internacional para resolver os problemas mundiais de caráter econômico, social, cultural e humanitário, promovendo o respeito aos direitos humanos e às liberdades individuais" (UNIC).

A principal atuação da ONU para a efetivação de seus postulados se dá por meio da criação de documentos subscritos pelos seus membros e que buscam dar um norte para a atuação das nações em prol da consolidação dos direitos fundamentais. Quanto à questão do desenvolvimento econômico, várias são as cartas que articulam um conjunto principiológico, que serve de parâmetro para uma atuação globalizada no caminho do efetivo respeito aos direitos fundamentais.

O principal documento, para a concretude deste caminho, é a Carta da ONU de 1945 e, a partir dela, outros tantos documentos como 0 "Pacto Internacional dos Direitos Econômicos, Sociais e Culturais" e a "Declaração sobre o Direito ao Desenvolvimento" surgem para a criação de consenso mundial sobre os parâmetros do desenvolvimento econômico. Todos estes documentos influenciaram o texto constitucional brasileiro de 1988, que cria um sistema, no capítulo da ordem econômica, que delimita o exercício da atividade econômica a uma série de postulados de direitos fundamentais.

\section{BREVES CONSIDERAÇÕES SOBRE OBJETIVO DA CONSTRUÇÃO E EFETIVAÇÃO DOS DIREITOS FUNDAMENTAIS E O TEMA PROPOSTO}

Agir em sintonia com os princípios de direitos fundamentais é agir dentro de uma ética da valorização e respeito à vida humana em sua amplitude e, ao estabelecer que estes atuam tanto vertical como horizontalmente, significa dizer que queremos uma nova ordem de relação tanto no plano individual, relação entre pessoas naturais e pessoas naturais, como no plano coletivo, relação entre pessoas naturais e pessoas jurídicas.

A construção histórica dos direitos fundamentais busca a efetividade de uma série de compromissos que possam ser capazes de tornar realidade uma vida social em que a paz não seja utopia, mas, sim, uma realidade, em que haja uma significativa diminuição de conflitos intersubjetivos e plurissubjetivos. Assim, teremos atuação estatal menor na área do Poder Judiciário, por diminuição das demandas e, por conseguinte, uma diminuição no aparelhamento das polícias e na diminuição na construção de presídios por falta de demanda, ou seja por falta de público. O principal compromisso dos direitos fundamentais é o de tornar a vida social menos violenta e para isto as pessoas (naturais, jurídicas públicas e privadas) devem adotar um novo comportamento pautado pelo respeito aos postulados de direitos fundamentais.

O importante no estudo dos direitos fundamentais é a sua horizontalização, em sua construção histórica, e esta visa, principalmente, a vincular o Estado aos ditames dos referidos direitos. 
A principal finalidade dos direitos fundamentais é de conferir aos indivíduos uma posição jurídica de direito subjetivo, em sua maioria de natureza material mas às vezes de natureza processual e, consequentemente, limitar a liberdade de atuação dos órgãos do Estado. Por esse motivo, cada direito fundamental constitui, na definição do constitucionalista alemão Goerge Jellinek (18511911) um "direito público subjetivo", isto é um direito individual que vincula o Estado. (DIMOULIS, MARTINS, 2009, p. 54)

Nos direitos fundamentais, percebe-se que a sociedade busca uma nova ética de comportamento e que as relações sociais sejam pautadas pelo efetivo compromisso com estes direitos e isto também tem um desdobramento no exercício da atividade econômica em que toda e qualquer relação, advinda desta atividade, devese pautar pelo respeito e efetivação dos referidos direitos.

A revolução industrial demonstrou 0 quanto a atividade econômica pode ser cruel com o ser humano. Existem relatos aterrorizadores de como o ser humano foi tratado naquele período, a partir dali percebeu-se o quão necessário era estabelecer os limites do exercício desta atividade.

Os princípios consagradores dos direitos humanos querem também ser o referencial para uma atividade econômica cada vez mais subordinada aos seus ditames.

\section{ATIVIDADE ECONÔMICA E NECESSÁRIA SUBORDINÇÃO À DIGNIDADE DA PESSOA HUMANA POR EXPRESSA VONTADE DAS CARTAS DA ONU}

De acordo com o artigo XXV da Declaração Universal dos Direitos do Homem observamos "Todo ser humano tem direito a um padrão de vida capaz de assegurar-Ihe, e a sua família, saúde e bem-estar, inclusive alimentação, vestuário, habitação, cuidados médicos e os serviços sociais indispensáveis, e direito à segurança em caso de desemprego, doença, invalidez, viuvez, velhice ou outros casos de perda dos meios de subsistência em circunstâncias fora de seu controle".

A questão que se impõe é localizar as formas e os meios para que o ser humano atinja o padrão de vida proposto pela Declaração e a atividade econômica esta intimamente ligada a essa possibilidade:

O comércio e o mercado são fenômenos humanos vitais: idéias e práticas que, a partir do momento em que foram desenvolvidas, permitiram 0 estabelecimento de um ciclo de prosperidade, fruto da superação da dimensão egoística da existência dos grupos isolados, superada pela dimensão universalista do intercâmbio, com as múltiplas vantagens dele decorrentes, dele permitindo não só a circulação de recursos necessários para a subsistência mínima; permitindo, para além, a circulação de recursos úteis para o estabelecimento de uma existência confortável, que vence a mera sobrevivência. $A$ qualidade material de vida do ser humano contemporâneo é uma prova eloqüente da importância do comércio na história da humanidade: um amplo mercado mundializado fornece aos seres humanos toda a sorte de benefícios: alimentos, roupas, medicamentos, educação, entretenimento etc. (MAMEDE, 2010, p. 1-2)

O primeiro compromisso da atividade econômica com os direitos fundamentais se relaciona à efetivação da dignidade da pessoa humana por meio de amparo ao ser humano nas suas diversas necessidades, não só de mera 
sobrevivência, como alimentação, mas uma sobrevivência qualificada por toda a sorte de recursos que surgem desta atividade econômica organizada, fruto do desenvolvimento tecnológico.

O desenvolvimento tecnológico, que promove o aprimoramento dos diversos bens que oferece ao ser humano, um padrão de vida capaz de assegurar-lhe uma vida digna, e a sua família, saúde e bem-estar, é fruto do ideal de livre concorrência, um mecanismo de controle da atuação econômica pela livre iniciativa.

Em 1966, a Assembléia Geral da ONU, via resolução 2200-A (XXI), firma o Pacto Internacional dos Direitos Econômicos, Sociais e Culturais e, em seu artigo $11^{\circ}$ traça as linhas do compromisso que o desenvolvimento econômico deve ter com a construção da dignidade da vida humana.

1 - Os Estados-Signatários no presente Pacto reconhecem 0 direito de toda a pessoa a um nível de vida adequado para si e sua família, incluindo alimentação, vestuário e habitação adequados e a uma melhoria contínua das suas condições de vida. Os EstadosSignatários tomarão medidas apropriadas para assegurar a efectividade deste direito, reconhecendo para esse feito, a importância essencial da cooperação internacional baseada no livre consentimento. 2 - Os EstadosSignatários no presente Pacto, reconhecendo 0 direito fundamental de toda a pessoa a estar protegida contra a fome, adoptarão, individualmente e através da cooperação internacional, as medidas, incluindo programas concretos, que sejam necessários para: a) Melhorar os métodos de produção, conservação e distribuição de alimentos através da plena utilização dos conhecimentos técnicos e científicos, da divulgação de princípios sobre nutrição e do aperfeiçoamento ou da reforma dos regimes agrários de modo a que se atinja uma exploração e utilização mais eficazes das riquezas naturais;

A Assembléia Geral da ONU em 1986, ao apresentar os termos da Declaração sobre o Direito ao Desenvolvimento reafirma que

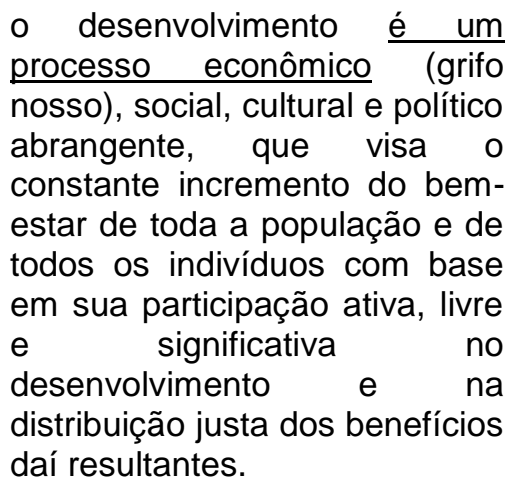

Todos os documentos históricos citados ratificaram a necessidade de que 0 desenvolvimento econômico apresentasse um compromisso com a efetivação do princípio da dignidade da pessoa humana. E este documento, juntamente com outros, como a constituição de Weimar, que dizia que "A organização da vida econômica deverá realizar os princípios da justiça, tendo em vista assegurar a todos uma existência conforme a dignidade humana [...]", demonstram que já desde muito tempo há uma preocupação em harmonizar desenvolvimento com a efetiva melhora no padrão de vida das pessoas com o efetivo desdobrar de amparo deste desenvolvimento com a realização da dignidade da pessoa humana.

\section{O TEXTO CONSTITUCIONAL DE 1988 E A ORDEM ECONÔMICA.}

O texto constitucional brasileiro traz, no título VII, dispositivos que demonstram o compromisso que a atividade econômica e, por conseguinte, o desenvolvimento econômico tem com os direitos fundamentais $e$ isto se faz presente principalmente em incisos do artigo 170 e no próprio caput.

O importante compromisso do Estado Brasileiro com os direitos fundamentais é com o 
principio da dignidade da pessoa humana, tanto na atuação geral do Estado como ente regulador da atividade econômica.

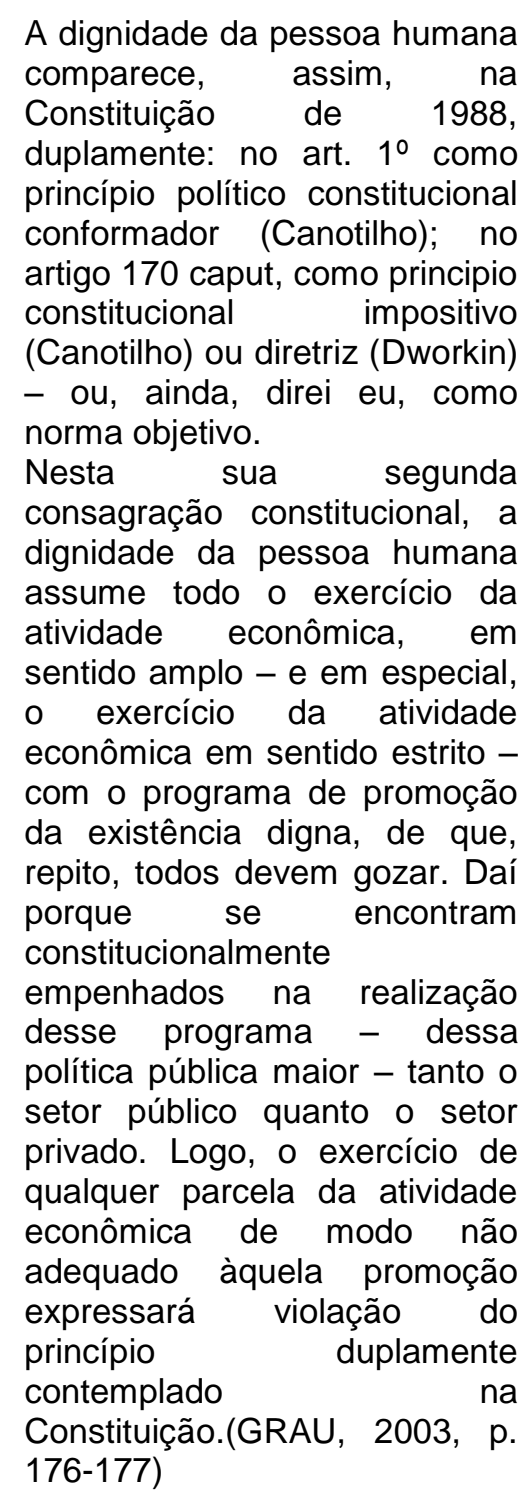

Nota-se que um importante compromisso da carta de 1988, com os direitos fundamentais, está explicitado no inciso III do artigo 170, que trata da função social da propriedade. Isto demonstra cabalmente que a propriedade, apesar de privada, tem de ser utilizada de acordo com os interesses coletivos. A iniciativa privada não pode utilizar-se dos meios de produção como quiser e da forma que quiser, pois estes têm uma função social.

A defesa do consumidor é outro postulado de direitos fundamentais que se encontra albergado pelo texto constitucional e o grande desdobramento desta vontade do legislador constituinte se faz notar no Código de Defesa do Consumidor (Lei no 8078/90). Isto significa que toda atividade econômica tem que ter "[...] por objetivo 0 atendimento das necessidades dos consumidores, o respeito à sua dignidade, saúde e segurança, a proteção de seus interesses econômicos, a melhoria da sua qualidade de vida, bem como a transparência e harmonia das relações de consumo [...]" art. $4^{\circ}$ do CDC.

Outra preocupação do Estado com a ordem econômica brasileira é que estivesse estruturada com a "defesa do meio ambiente, inclusive mediante tratamento diferenciado conforme o impacto ambiental dos produtos e serviços e de seus processos de elaboração e prestação" (inciso IV do artigo 170). A atuação estatal para efetivação desta vontade protetiva se faz notar, por exemplo, nos procedimentos de licenciamento ambiental, precedido de estudos de impacto ambiental que se documenta em relatórios de impacto ambiental. A preocupação do Estado com a questão ambiental é tanta que criou um capítulo inteiro, no texto constitucional (capítulo VI) para tratar do tema e firmar os princípios básicos para a efetivação da proteção ao meio ambiente.

O federalismo já é uma forma de organizar o Estado com vista a superar as desigualdades sociais dentro de sua base territorial, mas a atividade econômica também tem este compromisso. Igualmente, no capítulo da Constituição que trata dos princípios da atividade econômica, tem-se 0 necessário comprometimento da atividade econômica com "a redução das desigualdades regionais e sociais". (inciso VIl do art. 170 da CF)

A busca do pleno emprego com a valorização do trabalho humano demonstra finalmente que o nosso texto constitucional foi influenciado por todos os documentos da ONU, 
que traçam 0 ideal de desenvolvimento econômico com respeito ao principal beneficiário deste, o ser humano.

\section{CONCLUSÃO}

O texto constitucional de 1988, no que tange ao desenvolvimento econômico, está ligado à vontade globalizada de efetivação de um conjunto de princípios fundamentais, baseado no respeito aos direitos fundamentais e alinhavado pelas cartas da ONU, descritos neste artigo.

É patente o elevado nível de nosso texto constitucional quanto ao desdobramento dos postulados das Cartas da ONU, ou seja, o texto avança de forma significativa trazendo um conjunto harmônico de princípios que estruturam um grande sistema de proteção.

Pode-se notar a existência de um sistema, visto que 0 ideal de proteção da dignidade da pessoa humana se desdobra, como demonstrado no item 4, em diversos postulados de proteção e que estão em harmonia.

A dignidade da pessoa humana não se efetiva sem que à propriedade seja dada uma função social, ou seja, toda e qualquer propriedade que compõe os meios de produção deve atender, principalmente, ao seu fim social. Nota-se que as empresas, cada vez mais, têm uma responsabilidade social e a limitação ao direito de propriedade tem sintonia com esta realidade. Realça-se que esta limitação não tem a mesma natureza da proposta pelo modelo Comunista de Estado.

O texto constitucional de 1988, no que tange à ordem econômica, reafirmou um Estado do bem-estar social, apesar da tendência mundial, em que, nas palavras de Fabio Ulhoa Coelho, "opera-se a desarticulação do estado do bem-estar social nas economias centrais do bloco capitalista (o antigo "primeiro mundo")". (Ulhoa, 2007, p. 5)
Este Estado do bem-estar social, comprometido com a efetivação do princípio da dignidade da pessoa humana, afirma também um compromisso com a defesa do meio ambiente, com a busca do pleno emprego, com a defesa do consumidor, com a redução das desigualdades sociais.

Nota-se que há um todo harmônico, ou seja, a dignidade da pessoa humana não se efetiva sem que haja respeito ao meio ambiente, sem que haja busca do pleno emprego, sem que haja uma redução das desigualdades regionais, sem que o consumidor seja tratado de forma diferenciada.

O principal meio de proteção ao ser humano é o de valorização de seu trabalho em que a ordem econômica deve assegurar "a todos existência digna, conforme os ditames de justiça social." (BRASIL, CF art. 170)

\section{REFERÊNCIAS}

CENTRO de Informação das Nações Unidas UNIC - Rio de Janeiro. Disponível em: $<$ http://unicrio.org.br/conheca-a-onu/propósitos-eprincipios-da-onu>. Acesso em: 18/08/2010.

COELHO, F. U. Curso de Direito Comercial. 11.ed. São Paulo: Saraiva, 2007, v. 1.

DIMOULIS, D.; MARTINS, L. Teoria Geral dos Direitos Fundamentais. 2.ed. São Paulo: Revista dos Tribunais, 2009.

GRAU, E. R. A ordem Econômica na Constituição de 1988 (Interpretação e crítica). 8.ed. São Paulo: Malheiros Editores, 2003.

MAMEDE, G. Direito empresarial brasileiro: empresa e atuação empresarial. 4.ed. São Paulo: Atlas, 2010. v. 1. 